LA W RENCE LIVERMORE N A TIO NAL LABORATORY

Summary of Current LLNL Projects with the Russian Federation

\author{
O. Schilling
}

April 5, 2012 
This document was prepared as an account of work sponsored by an agency of the United States government. Neither the United States government nor Lawrence Livermore National Security, LLC, nor any of their employees makes any warranty, expressed or implied, or assumes any legal liability or responsibility for the accuracy, completeness, or usefulness of any information, apparatus, product, or process disclosed, or represents that its use would not infringe privately owned rights. Reference herein to any specific commercial product, process, or service by trade name, trademark, manufacturer, or otherwise does not necessarily constitute or imply its endorsement, recommendation, or favoring by the United States government or Lawrence Livermore National Security, LLC. The views and opinions of authors expressed herein do not necessarily state or reflect those of the United States government or Lawrence Livermore National Security, LLC, and shall not be used for advertising or product endorsement purposes.

This work performed under the auspices of the U.S. Department of Energy by Lawrence Livermore National Laboratory under Contract DE-AC52-07NA27344. 


\title{
Summary of Current LLNL Projects with the Russian Federation
}

\author{
Oleg Schilling
}

Project Title: Molecular Dynamics Investigation

Russian Institute: Russian Federal Nuclear Centre-Institute of Technical Physics (RFNCVNIITF)

\section{Brief Description:}

Developing a sophisticated theory to understand the electronic structure of $5 \mathrm{f}$-metals is a great challenge to solid state physics. Complicated electronic structures of $5 \mathrm{f}$-metals make their properties strongly sensitive to small energy changes produced by the addition of a small amount of alloy, impurities, or crystal structure defects caused by irradiation. A theoretical material science technique applicable to investigate these effects is atomistic simulation using Classical Molecular Dynamics (CMD). In contrast to ab initio techniques, CMD may include several million particles, so that there is a possibility of direct simulation of very low concentration impurities and defects (as well as phenomena such as plasticity and polymorphous transitions) under given conditions.

\section{Purpose of work:}

Our goal is to develop theoretical models to understand and predict changes in materials properties of actinides caused by self-irradiation.

\section{Publications:}

V. V. Dremov, F. A. Sapozhnkov, M. A. Vorobyova, G. V. Ionov, A. V. Karavaev, and B. Chung, "Direct MD modeling of the effect of self-irradiation on mechanical properties of $\mathrm{Pu}$ when static and dynamic loading", Tenth International Workshop: Fundamentals of Plutonium, July 2010.

V. V. Dremov, A. V. Karavaev, F. A. Sapozhnikov, M. A. Vorobyova, D. L. Preston, and M. A. Zocher, "Molecular dynamics evaluation of the impact of Ga, He, and vacancy concentration on the mechanical properties of Ga-stabilized $\delta$-Pu," Journal of Nuclear Materials 414, 471-478 (2011).

\section{PI of the project:}

Brandon Chung, LLNL

Vladimir Dremov, VNIITF 
Project Title: Study of Relativistic Discrete Variational (RDV) Methods

Russian Institutes: Russian Federal Nuclear Centre-Institute of Technical Physics (RFNCVNIITF), Institute of Solid State Chemistry (ISSC), Russian Academy of Sciences, Ekaterinburg, Russia, and Institute Nuclear Research (INR), Russian Academy of Sciences, Moscow Russia

\section{Brief Description:}

Theoretical part. RDV cluster calculations of the electronic configuration of fcc plutonium metal. RDV investigations of: (1) the fully relativistic electronic and chemical bonding structures as well as the electronic configuration in plutonium dimer; (2) the chemical bonding structure and atomic orbital populations for the central $\mathrm{Pu}$ atom in a Pu19 cluster with geometry and boundary conditions corresponding to the fcc Pu lattice, and; (3) the electronic structure of large Pu79 and Pu201 clusters with crystal-lattice boundary conditions.

Experimental part. Development of experimental facilities for basic research of actinides: installation of X-ray powder diffractometer with imaging plate detector and diamond anvil cell, calibration and test experiments.

\section{Purpose of work:}

Our goal is a better understanding of the electronic structure of actinides, particularly plutonium.

\section{Publications:}

M. V. Ryzhkov, A. Mirmelstein, S.-W. Yu, and J. G. Tobin, "Probing Actinide Electronic Structure through Pu Cluster Calculations," Physical Review B, submitted February 2012.

M. V. Ryzhkov, A. Mirmelstein, S.-W. Yu, and J. G. Tobin, "Probing Actinide Electronic Structure through Pu Cluster Calculations," Pu Futures Meeting, Cambridge, UK, July 2012, accepted for poster presentation.

J. G. Tobin, S.-W. Yu, B. W. Chung, M. V. Ryzhkov, and A. Mirmelstein, "Comparison of Spectroscopic Data with Cluster Calculations of Plutonium, Plutonium Dioxide and Uranium Dioxide," AVS International Symposium, Tampa Bay, FL, November 2012, abstract submitted, March 2012.

\section{PI of the project:}

James Tobin, LLNL

Alexey Mirmelstein, VNIITF 
Project Title: Beryllium Dynamic Strength Measurements

Russian Institute: Russian Federal Nuclear Centre-Institute of Experimental Physics (RFNCVNIIEF)

\section{Brief Description:}

Use high explosives driven Rayleigh-Taylor instability growth technique to infer the strength of beryllium under dynamic loading conditions at pressures near $0.5 \mathrm{Mbar}$ and strain-rates $\sim 10^{5}$ per second. We will also use high-explosive loading to drive flat-plate experiments that will be recovered and analyzed for deformation modes (shear bands/twins, etc).

\section{Purpose of work:}

We will be conducting high pressure, high strain-rate experiments on the National Ignition Facility (NIF) for other materials (e.g., tantalum), which need heat shield materials to protect them from melting in the hot plasma environment. Beryllium serves as a good heat shield because its high sound speed allows for the transmission of the loading wave without causing it to steepen into a shock and thereby shock-melt the sample under study. However, since beryllium has strength, it is necessary to understand the possible effects of the beryllium strength on the strength properties of the sample of interest. Thus, we are conducting these experiments to understand better how the current strength models for beryllium will affect the interpretation of our NIF data.

\section{Publications:}

The contract is beginning the final phase, which is to conduct the experiments this summer (targets are currently being fabricated). No data, and therefore, no publications exist yet.

\section{PI of the project:}

Robert Cavallo, LLNL

Victor Raevsky, VNIIEF 